\title{
Multi-criteria decision making for urban built heritage conservation: application of the analytic hierarchy process
}

Received (in revised form): 15th September, 2008

\begin{abstract}
Yung Yau
is currently conducting research and lecturing in the City University of Hong Kong. Before joining the university, he practised building control in the Buildings Department, the Government of Hong Kong Special Administrative Region. His research interests include housing studies, urban renewal, heritage conservation, real estate economics and finance, and building performance assessment.
\end{abstract}

Correspondence: Yung Yau, Department of Public and Social Administration, City University of Hong Kong, Tat Chee Avenue, Kowloon, Hong Kong; Tel: + 8522788 8958; Fax: + 85227888926

\begin{abstract}
Conservation of built cultural heritage is never an easy task, especially when the subject heritage is located in a heavily developed urban area. The enduring controversy over the conservation scheme of the former Central Police Station Compound in Hong Kong has highlighted the difficulties in achieving satisfying decisions in conservation projects by way of private sector participation. The crux of the deadlock lay in the different perceptions of the project stakeholders towards the relative importance of different decision-making criteria. In fact, many challenges of this kind associated with built heritage conservation can be modelled as multi-criteria decision making (MCDM). The main objective of this study is to present an MCDM model on the criteria for decision making, which can have many applications in heritage conservation decision making. To this end, a preliminary MCDM framework for project selection is developed using the analytic hierarchy process (AHP), which has been widely applied to MCDM in many other fields. Using this framework, 20 local building professionals were interviewed to solicit their views on the relative importance of the decision criteria. It is contended that the AHP provides a scientific approach to the quantification of the relative importance of various decision-influencing criteria. In addition, the use of the AHP will help the government and community identify projects with the best potential to deliver satisfactory outcomes in a project selection process that is not based simply on the highest bid. Journal of Building Appraisal (2009) 4, 191-205. doi:10.1057/jba.2008.34
\end{abstract}

\section{Keywords:}

analytic hierarchy process, built heritage conservation, multi-criteria decision making, private participation, Hong Kong

\section{INTRODUCTION}

Conservation of built cultural heritage is one of the essential factors in the long-term prosperity of a city (Chu and Uebegang, 2002). Yet, it has never been an easy task to conserve built cultural heritage, especially in heavily developed urban areas. In Hong Kong, where developable land is highly limited and population is sizeable, built heritage conservation has been confronted with challenges (Cuthbert, 1983; Lung, 1994; Hsu, 2001). Largely due to economic forces and land management policy, Hong Kong has 
enjoyed the fruitful results of rapid development over the past four decades at the cost of losing the very social, cultural, and environmental fabric in her cityscape. Accompanied by urban growth, these development-led changes recurrently involve the destruction of idiosyncratic and significant buildings and wiping out the tangible expressions of the long-ago indigenous ways of life during the colonial days of the city. Since the mid1970s, the local government has been empowered to protect cultural heritage in the city.

Nonetheless, heritage conservation is by no means an inexpensive exercise. The cost of restoring a historic building can reach tens of millions, and the annual maintenance cost can also be substantial. Given that the Asian Financial Crisis in 1997 weakened the ability of the government to deal with the ever-growing financial burden arising from the conservation of cultural heritage in the territory, sole reliance on government funding was no longer realistic. Although heritage tourism has been widely proposed (eg Henderson, 2002; Li and Lo, 2005), it still has a long way to go before it is well developed enough to financially contribute conservation activities. In this light, in the late 1990s the local government started exploring opportunities for developing mechanisms for the involvement of the private sector in heritage conservation projects in Hong Kong, with a due account of the successful overseas experiences such as Covent Garden in London and Faneuil Hall in Boston. Since then, the model of public-private partnering (PPP) has been considered for tapping into resources from the private sector and imaginative ideals for turning historic assets into beneficial uses.

In spite of its benefits, the PPP model does not work best in all situations. Since the Hong Kong government proposed to invite the private sector to participate in the conservation of the former Central Police Station Compound, there have been a lot of concerns and disputes over the project. The crux of the deadlock in the project rests on the lack of a fair and systematic bid evaluation scheme, particularly when numerous decision criteria are taken into account, that could satisfy the project's stakeholders, including the developers, government officials, conservationists, and general public. Against this background, the objective of the paper is to rationalise the decision-making process for built heritage conservation in Hong Kong. In fact, many challenges of this kind can be modelled as multi-criteria decision making (MCDM). In this regard, an MCDM framework is developed in this study, aiming to illustrate how decision making for built heritage conservation can be achieved in a credible manner. The extension of this framework can have many applications in heritage conservation decision making.

\section{THE CENTRAL POLICE STATION COMPOUND AS A BATTLEFIELD}

Although the legal instrument for heritage conservation in Hong Kong, that is the Antiquities and Monuments Ordinance, was enacted in 1976, the roles of conserving cultural built heritage remained in the public domain. Perhaps, the first private sector involvement in the matter was the archaeological discovery in Ma Wan Island in 1993. Sun Hung Kai Properties Limited, one of the largest local developers in Hong Kong, discovered an archaeological site in the working site for a massive residential development. The developer later funded the resulting excavations (Chu and Uebegang, 2002). Since then, however, the Hong Kong government had not taken any bold and determined step to institutionalise the participation of the private sector in heritage conservation until the late 1990s. In view of the heavy deficits in the public account after the Asian Financial Crisis, the local government had to resort to private resources to conserve built heritage which was large in scale. At about the same time, there was a growing body of research suggesting the possible economic benefits brought about by built heritage conservation (eg Chang et al., 1996; Bizzarro and Nijkamp, 1997) and the 
possibility of having the private sector involved in the conservation process (eg Kiang, 2004; Aas et al., 2005). An ideological change in the heritage conservation then evolved. The approach adopted by the western world has moved from 'curatorial approach' to 'tourism business'. In the former approach, preserving the heritage in a pristine stage is put on the top of the agenda. Financial viability and accessibility to the public are only secondary considerations (Leask and Goulding, 1996). In contrast, economic management of the heritage is the primary goal in the latter approach (Croft, 1994). The monetary gain is perceived as essential for tackling the considerable backlog of urgent maintenance and repair work.

After a lengthy consultancy study, the Hong Kong government finally proceeded with the PPP model for built heritage conservation, and invited the private sector to submit proposals to preserve and develop the Former Marine Police Headquarters (FMPHQ) in Tsim Sha Tsim in November 2002. ${ }^{1}$ Finally, the Flying Snow Limited, a wholly owned subsidiary of Cheung Kong (Holdings) Limited, was awarded the tender to develop the site into a heritage tourism facility. With the successful experience in the FMPHQ project, the Hong Kong government unveiled a plan in April 2003 to invite proposals from the private sector to formulate a heritage tourism project involving the former Central Police Station, Victoria Prison, and the Central Magistracy (hereinafter 'the Compound') in the Central District. Built between 1841 and 1914 but preserved in its original form and integrity, the Compound is an excellent and rare example of Victorian and Edwardian Colonial architecture in the territory. Figures 1-3 present the images of the Compound.

It was the government's original plan to award the project through an open competitive process. The successful candidate would be awarded a 50-year land grant (Hong Kong Special Administrative Region Government, 2004). As the prudent preservation of the built heritage is the key objective of the project, the proponents were required to propose in detail how the preservation objectives could be fulfilled. At the same time, as operations of the Compound had to be financially sustainable in both conservation and occupation stages, the proponents were required to demonstrate their financial capabilities to undertake the project. These requirements were determined through consultation with

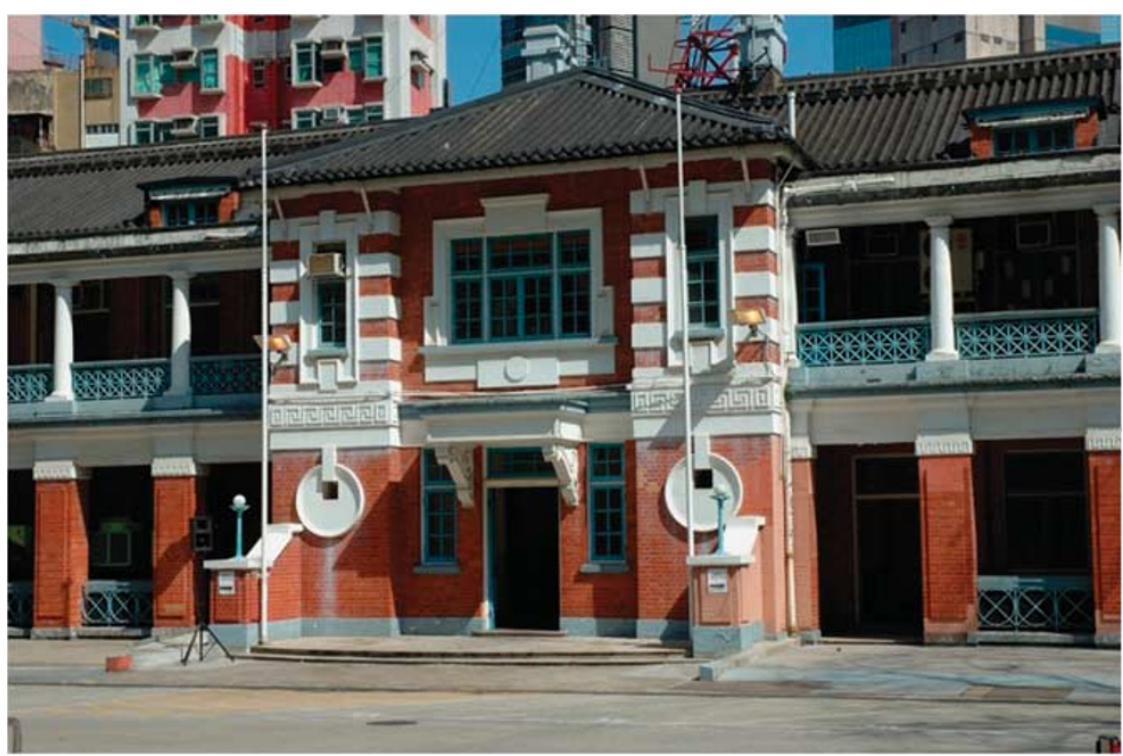

Figure I: Front elevation of the Victoria Prison 


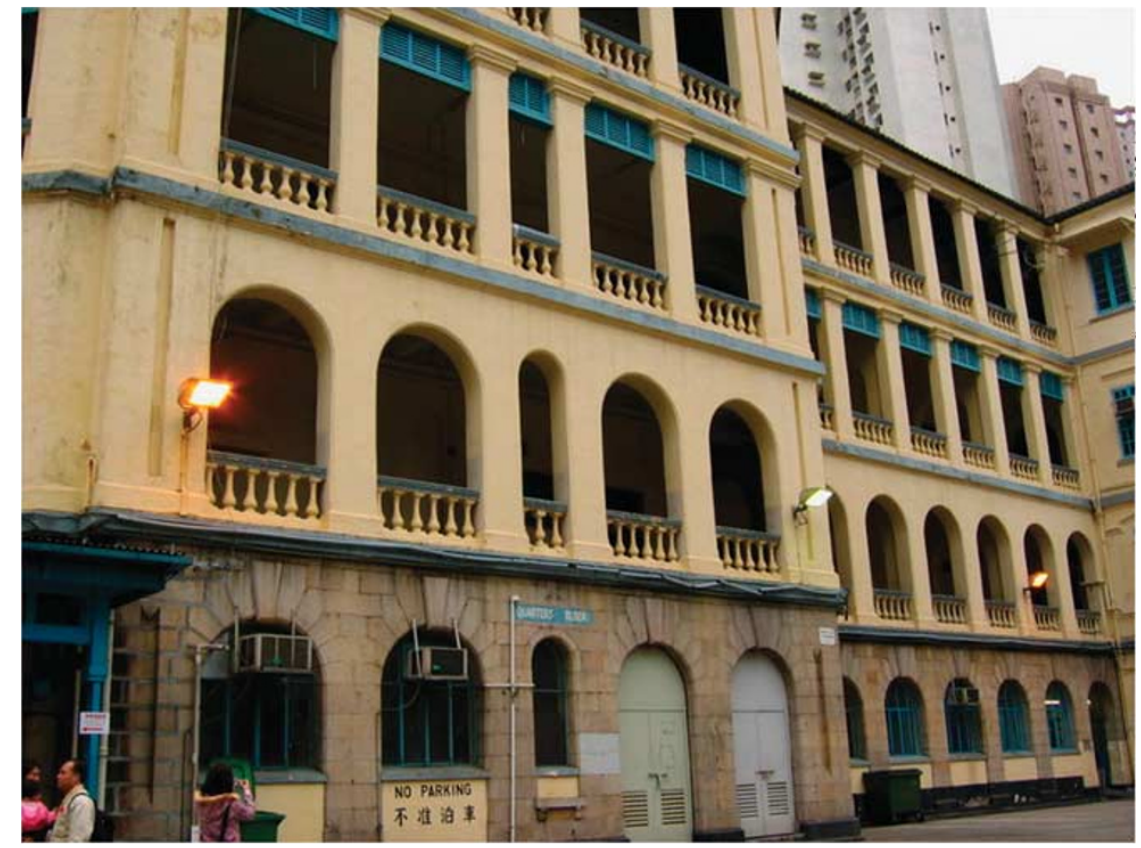

Figure 2: Rear elevation of the Central Police Station

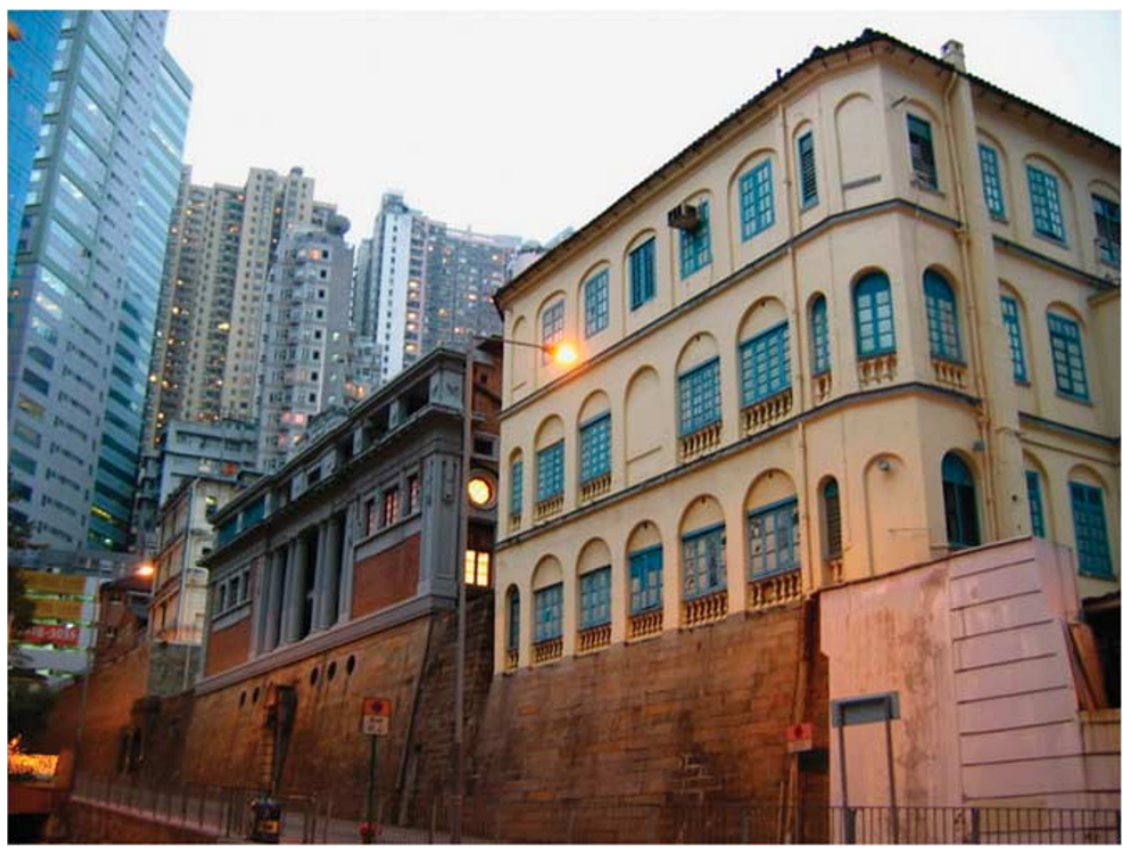

Figure 3: Side elevation of Victoria Prison and Central Police Station

the Antiquities Advisory Board. In spite of these requirements, the proponents would be allowed litheness to incorporate commercial elements such as retail and entertainment facilities in the project in a creative manner, provided that these elements suited the unique character and setting of the site (Hong Kong Special Administrative Region Government, 2004). 
To speed up project implementation, the Hong Kong government intended to call for tenders in early 2004. According to the government's plan, the site would be handed over to the successful tenderer in phases in 2005. Yet, since the disclosure of the government's plan to the public, the local community has opposed the government's intent to submit the historic site to the private sector's whims (South China Morning Post, 2004a, b). The oppositions mainly rested on the grounds that any financial gain from the project had been over-emphasised and may outweigh the benefits of the project to the community. Upholding the primary objectives of the preservation project, local community groups requested that qualitative aspects of proposals should attract a higher emphasis than the premium in the tender assessment. The selection criteria for the successful tenderer should be reviewed to reflect the community's aspirations for the future of heritage buildings before tendering. Nevertheless, the government insisted that the weightings of the criteria were reasonable. Such a controversy has put the tendering process on hold and delayed the project's implementation. ${ }^{2}$

\section{THE MULTI-CRITERIA APPROACH FOR DECISION MAKING}

From the above, the deadlock of the conservation project of the Compound exemplifies obviously the divergent views of the stakeholders, namely the government, the private sector, and the community, towards the importance of different criteria of consideration. In fact, this is not the only story in the world. Ongoing decisions for urban heritage conservation are being made by different parties every day (Hutter, 1997). By their nature, these decision makers need to consider complex criteria such as integrity, reversibility, degree of intervention, financial benefits, reliability, loading posed on infrastructure, and influence to residence nearby. In most cases, these criteria compete with each other. This makes the decision-making process difficult, particularly when a large number of criteria are involved.

\section{Multi-criteria decision making}

To ease the difficulties in decision making involving a number of decision criteria, various models for MCDM have been developed and serve as critical decision tools for many political, financial, scientific, and engineering revolutions, in which alternatives needed to be prioritised (McIntyre and Parfitt, 1988; Bouyssou and Vincke, 1997; Wong, 1999). Generally, MCDM relies on three fundamental steps. What comes first is the identification of alternatives for the selection and criteria of decision making, according to the overall project objective or goal. For example, the objective of a conservation project is to revitalise a built cultural heritage within urbanised environs. With due observation of the project objective, a list of proposals (eg converting the heritage into a restaurant and museum with little disturbance to the heritage) is proposed, and a roll of considerations (eg congruity with the surroundings, disturbances to the historical integrity of the heritage, and the loading on local infrastructure) are identified. Secondly, it is necessary to determine how the criteria affect the final choice. The association between the criteria and objectives needs to be specified. In this stage, questions on the formula specification and assessment of the relative importance (ie the weights) of the criteria arise. Finally, the performance of the alternatives with respect to these criteria has to be evaluated and processed to provide a single rate for each alternative. Then the alternatives can be ranked.

Consider a scenario with $M$ criteria and $N$ alternatives. The criteria are denoted as $C_{i}$ (for $i=1,2,3, \ldots, M$ ) and the alternatives as $A_{j}($ for $j=1,2,3, \ldots, N)$. For each $C_{i}$, its relative importance or weight to the overall objective of the project is given by $W_{i}$. For simplicity, 
it is assumed that all $W_{i}$ values are always summed to a unity. The performance of alternative $A_{j}$, as rated by the assessors with respect to the criterion $C_{i}$, is denoted by $a_{i j}$. As aforementioned, a single rate is essential for comparing the performance of different alternatives. This indicator can result from the aggregation of the criteria's weights and performance. Although there are a number of specifications for the aggregation for MCDM, the weighted arithmetic mean is certainly the simplest but widest used algorithm. This specification is also adopted for our proposed MCDM model, and thus the final preference $P_{j}$ of the alternative $A_{j}$ is given by

$$
P_{j}=\sum_{i=1}^{N} a_{i j} W_{i} \quad \text { for } j=1,2,3, \ldots, N
$$

In other words, this preference $P_{j}$ is the product of aggregation if all the decision criteria are considered simultaneously. Without loss of generality, the best alternative is one characterised with the largest preference value because of the exercise of maximisation, which is built upon the assumption of additive utilities. The performance of an alternative with respect to the individual decision criteria can be rated either objectively or subjectively. As for the weightings or relative importance of the criteria, it has been a rather controversial issue. In the absence of objective empirical evidence for computing the weightings (eg the relative impact of an attribute on the success of a heritage conservation project), recourse has to be made to the use of subjective opinions from experts or laymen through multiple-criteria analysis techniques.

There has been abundant literature comparing the methods for assessing attribute weights (eg Schoemaker and Waid, 1982; Watson and Freeling, 1982; Pöyhönen and Hämäläinen, 2001). Without doubt, direct weighing (ie direct assignment of weightings to individual criteria or attributes) is the simplest approach among all. This method is usually facilitated with the use of structured checklists, and is easily understandable to laypersons. Regardless of its simplicity, however, direct weighing has been repeatedly evidenced to suffer from weighting biases (Bell et al., 2000), and inaccuracy due to limited cognitive capacity of decision makers, particularly when the number of attributes involved in each weight determination exercise is large. At the other extreme, the multiattribute utility model can generate weighting results with a high accuracy and reliability. Founded on studies by von Neumann and Morgenstern (1947) and Savage (1954), this approach is tailored to deal with the uncertainty among and interdependence between numerous attributes to be weighed. With the use of the multi-attribute utility model, subjective elements that tend to dominate the weight determination process can be minimised (Shen and Spedding, 1998). Even in its simplest version, nonetheless, the assessment process is still too complicated to operate. The operation of the multi-attribute utility model can be highly time consuming and expensive. In addition, the use of advanced mathematical equations in this approach limits its application to a small group of specialists.

\section{The analytic hierarchy process: An overview}

To strike a balance between theoretical robustness and practicability, the AHP is adopted for the evaluation of the criterion weightings in this study. Since being developed by Thomas L. Saaty in the early 1970s, the AHP has been widely used to help individuals and groups deal with MCDM problems (eg Saaty, 1980, 1988; Triantaphyllou and Mann, 1995). The model is structured as a logical hierarchy with at least three levels, namely the 


\section{LEVEL 1 \\ Goal \\ LEVEL 2 \\ Criteria \\ (and sub-criteria)}

\section{LEVEL 3}

Alternatives

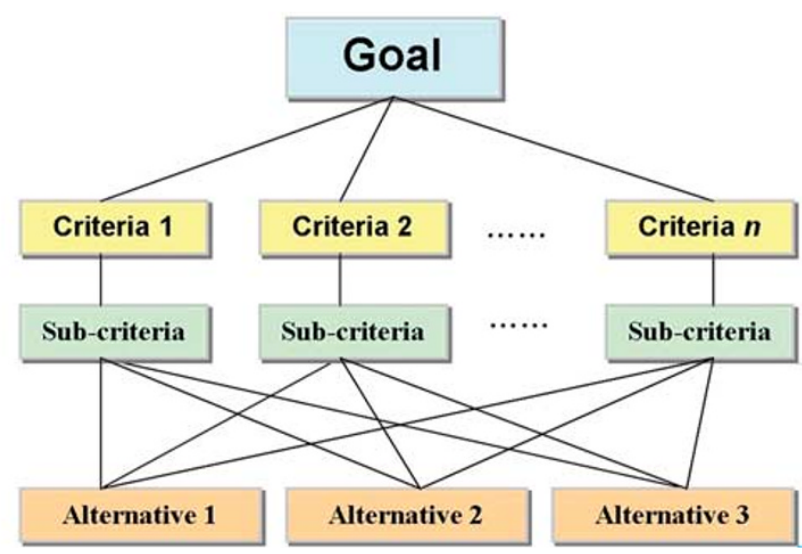

Figure 4: A typical hierarchy of AHP

goal, the criteria, and the alternatives, as shown in Figure 4. The AHP helps the decision makers evaluate the importance of every criterion in an intuitive manner by incorporating both subjective and objective data into the hierarchical framework.

In this regard, the AHP adopts pairwise comparisons to determine the relative importance of the criteria for meeting the goal. Being the heart of the approach, pairwise comparisons are made between the criteria, with respect to the goal, to decide on the relative importance of one criterion versus another (Saaty, 1980, 1988). The information from the pairwise comparison is represented in a pairwise comparison matrix. The number of comparisons increases with that of the criteria. A total of $n(n-1) / 2$ judgments are needed to evaluate the weightings of $n$ criteria. For these $n$ criteria $\left(C_{1}, C_{2}, \ldots, C_{n}\right)$ with their relative importance given by $w_{1}, w_{2}, \ldots, w_{n}$, respectively, the resultant pairwise comparison matrix is

$$
\begin{aligned}
& \begin{array}{cccc}
C_{1} & C_{2} & \ldots & C_{n}
\end{array} \\
& C_{1} \quad\left[\begin{array}{llll}
w_{1} / w_{1} & w_{1} / w_{2} & \ldots & w_{1} / w_{n} \\
w_{2} / w_{1} & w_{2} / w_{2} & \ldots & w_{2} / w_{n}
\end{array}\right. \\
& \begin{array}{l|lllll}
C_{2} & w_{2} / w_{1} & w_{2} / w_{2} & \ldots & w_{2} / w_{n}
\end{array} \\
& \begin{array}{c}
\vdots \\
C_{n}
\end{array}\left[\begin{array}{cccc}
\ldots & \ldots & \ldots & \ldots \\
w_{n} / w_{1} & w_{n} / w_{2} & \ldots & w_{n} / w_{n}
\end{array}\right]
\end{aligned}
$$

For instance, there are three assessment criteria $X, Y$, and $Z$ for a given goal $G$ of a project. The pairwise comparison begins with the answering of the question 'with respect to the goal $G$ : what is the importance of criterion $X$ over criterion $Y$ ?' by the decision maker. Then, similar questions 'with respect to the goal $G$ : what is the importance of criterion $X$ over criterion $Z$ ?' and 'with respect to the goal $G$ : what is the importance of criterion $Y$ over criterion $Z$ ?' are answered. Each of these pairwise comparisons involves assessing the relative importance of one criterion with respect to the other criterion using a ratio scale. A commonly used ratio scale is suggested by Saaty (1988), as shown in Table 1.

For instance, if a decision maker believes that criterion $X$ is absolutely more important than criterion $Y$ with respect to the goal $G$, a value of 9 to criterion $A$ expresses this judgment. If criterion $Z$ is moderately more important than criterion $Y$, a value of 3 can be assigned to criterion $Z$. The process goes on until all pairs of criteria have been compared. 
Table I: Fundamental ratio scale in pairwise comparison (Saaty, 1988)

\begin{tabular}{|c|c|c|}
\hline Intensity of importance & Definition & Explanation \\
\hline I & Equal importance & Two criteria contribute equally to the goal \\
\hline 3 & Weak importance of one over another & $\begin{array}{l}\text { Experience and judgment consider one } \\
\text { criterion slightly more important than } \\
\text { another }\end{array}$ \\
\hline 5 & Essential or strong importance & $\begin{array}{l}\text { Experience and judgment consider one } \\
\text { criterion strongly more important than } \\
\text { another }\end{array}$ \\
\hline 7 & Demonstrated importance & $\begin{array}{l}\text { A criterion is considered strongly more } \\
\text { important and its dominance demonstrated } \\
\text { in practice }\end{array}$ \\
\hline 9 & Absolute importance & $\begin{array}{l}\text { The evidence showing one criterion to } \\
\text { be more important than another is of the } \\
\text { highest possible order of confirmation }\end{array}$ \\
\hline $2,4,6,8$ & $\begin{array}{l}\text { Intermediate values between the two adjacent } \\
\text { judgments }\end{array}$ & When compromise is needed \\
\hline $\begin{array}{l}\text { Reciprocals of the } \\
\text { non-zero numbers above }\end{array}$ & $\begin{array}{l}\text { If criterion } i \text { has one of the above non-zero } \\
\text { numbers assigned to it when compared with } \\
\text { criterion } j \text {, then } j \text { has the reciprocal value when } \\
\text { compared with } i\end{array}$ & - \\
\hline
\end{tabular}

Table 2: A $3 \times 3$ pairwise comparison matrix for illustration

\begin{tabular}{llll}
\hline With respect to the goal & $\mathbf{X}$ & $\mathbf{Y}$ & $\mathbf{Z}$ \\
\hline$X$ & 1 & 9 & 3 \\
$Y$ & $1 / 9$ & 1 & $1 / 3$ \\
$Z$ & $1 / 3$ & 3 & 1 \\
\hline
\end{tabular}

In fact, this pairwise comparison process can be facilitated with the help of a decisionmaking hierarchy like the one shown in Figure 1. Factors listed at each level are perceived as important attributes that affect attributes at the upper level. On the basis of the pairwise judgments, a pairwise comparison matrix, as shown in Table 2, can be formed.

\section{Quantifying data by using pairwise comparisons}

From the pairwise comparison matrix, the eigenvector and the maximum eigenvalue could be calculated by using the eigenvector equation:

$$
M W=\lambda_{\max } W
$$

where $M$ is the pairwise comparison matrix, $\lambda_{\max }$ is the maximum eigenvalue, and $W$ is the column vector of the actual relative weightings of the criteria. Details of the resolution of this equation can be referred to the eigenvector methods suggested by Saaty (1980) and Triantaphyllou and Mann (1990). The eigenvector of each pairwise comparison matrix provides a regional priority ordering. After the results are synthesised, a global priority order of each alternative with respect to the goal is given by the synthesised eigenvector.

The judgments of the decision makers are, however, often inconsistent. Therefore, Saaty (1980) proposed using a consistency ratio to gauge the degree of inconsistency in the pairwise comparison. A consistency ratio of 0.10 or less is considered acceptable; 


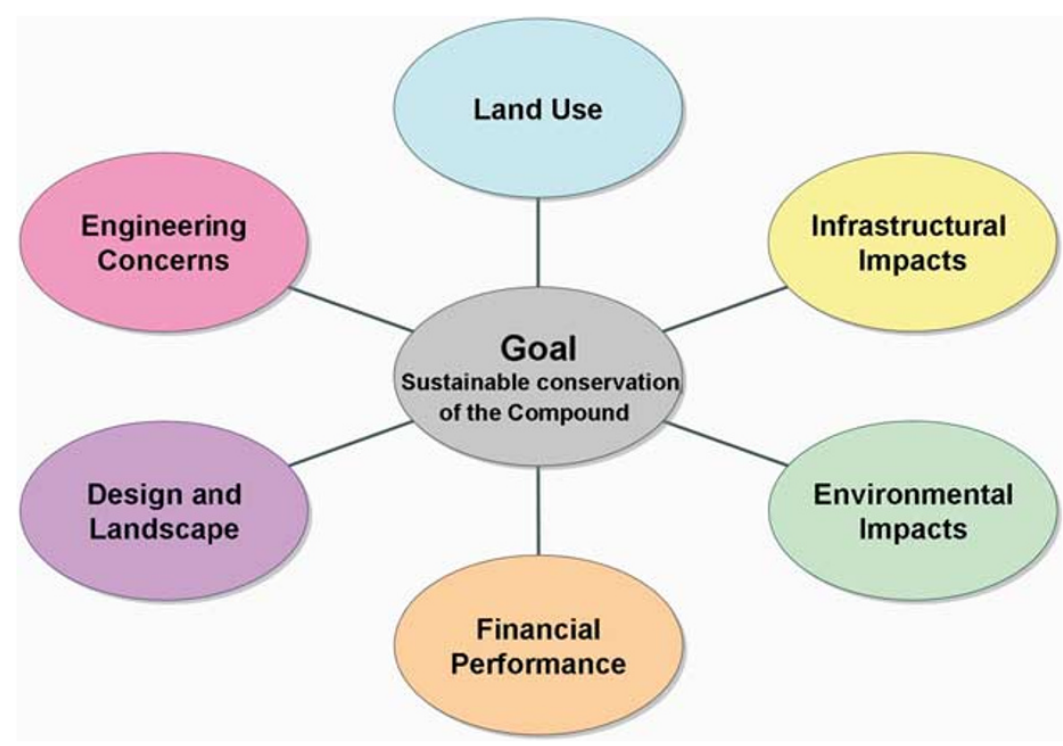

Figure 5: Criteria to be evaluated under the MCDM for conservation

otherwise some judgments need to be revised. In fact, all the analyses above are currently facilitated by the use of computer software such as Expert Choice ${ }^{\circledR}$. Synthesising the results of these analyses, the relative importance of the criteria meeting the goal can be computed.

\section{A PROPOSED MCDM MODEL FOR CONSERVATION PROJECTS}

As depicted above, the AHP is suited best to those MCDM problems in which an accurate quantification of the impacts of the alternatives on the decision-making problems is not possible. As one can see, the introduction and application of the AHP is to minimise the subjective elements that are predominant in the decision-making process and to increase the transparency of the prioritisation exercise. As reasonably expected, by making the processes more objective and transparent, the public accountability of a heritage conservation project will be improved. Hence, the AHP is ideally suited to the exercise of ranking alternative conservation proposals. This section presents an MCDM model that is based on the AHP mechanism tailored for decision making in conservation projects.

\section{Project goal and criteria for decision making}

As mentioned in the previous section, a clearly defined goal plays an important role in the MCDM. It dictates which criteria should be selected for the evaluation and how these criteria are weighted with reference to their importance to the success of the project. Regarding the case of the Compound, the goal is to conserve the built cultural heritage in a sustainable manner. As for criterion selection, as the invitation of the private sector to participate in urban built heritage conservation is still relatively new to Hong Kong, there have been only a few local references for the criteria identification. In this study, the criteria for evaluating various options were proposed based on City Planning Consultant Limited (City Planning Consultant Limited, 1996) and the Antiquities and Monuments Office (Antiquities and Monuments Office, 2000). As shown in Figure 5, six criteria are identified and used to evaluate the options provided by the private sector before the ranking was assigned. These criteria and their constituent sub-criteria are listed in Table 3. 
Table 3: Decision-making criteria and sub-criteria for heritage conservation

\begin{tabular}{|c|c|c|}
\hline Criterion & Sub-criterion & Description \\
\hline \multirow[t]{2}{*}{ Land use } & $\begin{array}{l}\text { Compatibility } \\
\text { Congruity }\end{array}$ & $\begin{array}{l}\text { Whether the proposed use of the heritage is suitable to the heritage } \\
\text { Whether the proposed use of the heritage is congruities with the } \\
\text { surrounding land uses }\end{array}$ \\
\hline & Historical integrity & $\begin{array}{l}\text { Impacts on the heritage brought about by the changes in the setting, } \\
\text { construction and future operations }\end{array}$ \\
\hline \multirow[t]{3}{*}{ Design and landscape } & Visual quality & Impacts of the completed project on the visual quality of the area \\
\hline & Development scale & $\begin{array}{l}\text { Whether the scale of new development in the site is excessive or } \\
\text { not }\end{array}$ \\
\hline & Barrier-free access & $\begin{array}{l}\text { Degree of accessibility to the site by people with different levels of } \\
\text { locomotive ability }\end{array}$ \\
\hline \multirow[t]{3}{*}{ Infrastructural impacts } & Transport system & Impacts on the existing transport network \\
\hline & Plumbing and drainage & Impacts on the existing water supply and drainage systems \\
\hline & Electricity and & Impacts on the existing electricity and gas supply systems \\
\hline \multirow[t]{3}{*}{ Environmental impacts } & Tree protection & Whether removal or transplantation of trees is required \\
\hline & Pollutions & $\begin{array}{l}\text { Whether the pollutions created by the conversion and construction } \\
\text { works are within acceptable levels }\end{array}$ \\
\hline & Nuisances & $\begin{array}{l}\text { Whether the nuisances created by the future operations are within } \\
\text { acceptable levels }\end{array}$ \\
\hline \multirow[t]{2}{*}{ Engineering concerns } & Structural conditions & $\begin{array}{l}\text { Structural soundness of the heritage and the feasibility to improve } \\
\text { the structural conditions to for the new use }\end{array}$ \\
\hline & Maintenance viability & $\begin{array}{l}\text { Whether the heritage is maintainable from a technical viewpoint } \\
\text { Geotechnical constraints imposed by the topology of the site }\end{array}$ \\
\hline \multirow[t]{3}{*}{ Financial performance } & Initial costs & $\begin{array}{l}\text { The amount of the costs associated with conversion and } \\
\text { construction }\end{array}$ \\
\hline & Recurrent costs & $\begin{array}{l}\text { The amount of annual recurrent maintenance expenses of the } \\
\text { heritage }\end{array}$ \\
\hline & Economic benefits & The amount of economic benefits generated by the project \\
\hline
\end{tabular}

There are some essential features of these selection criteria. First, all these criteria are of concern to the stakeholders of the conservation project. Secondly, the performance of an option on any one of these criteria can be judged independently of its performance on other criteria. Thirdly, no criterion is redundant (ie there are no two attributes that duplicate each other because they actually represent the same thing). In addition to the standard criteria listed above, some special criteria, such as legal requirements and special conservation policies, also need to be considered when assessing the option rankings. These special criteria sometimes override the standard criteria. For instance, a low ranking could be assigned to an option that does not observe the legal requirement for providing barrier-free access, whereas a higher ranking would be assigned to an option that addresses the policy need to create more tourist attractions in the territory.

\section{Weight setting and option ranking}

To illustrate how the AHP can be used for the MCDM for heritage conservation, a pilot study was conducted in the summer of 2007 . Twenty local building professionals ${ }^{3}$ were interviewed, following a set of structured procedures as shown in Figure 6. The interviews aimed to obtain pairwise comparison judgments from the professionals. Before the start of the pairwise comparisons, the interviewees should be clearly delivered with the background and goal of the conservation of the Compound. Terms that are too technical or unconventional were also clearly explained to the interviewees. These steps are essential for ensuring the consistency of understanding of the project among the 


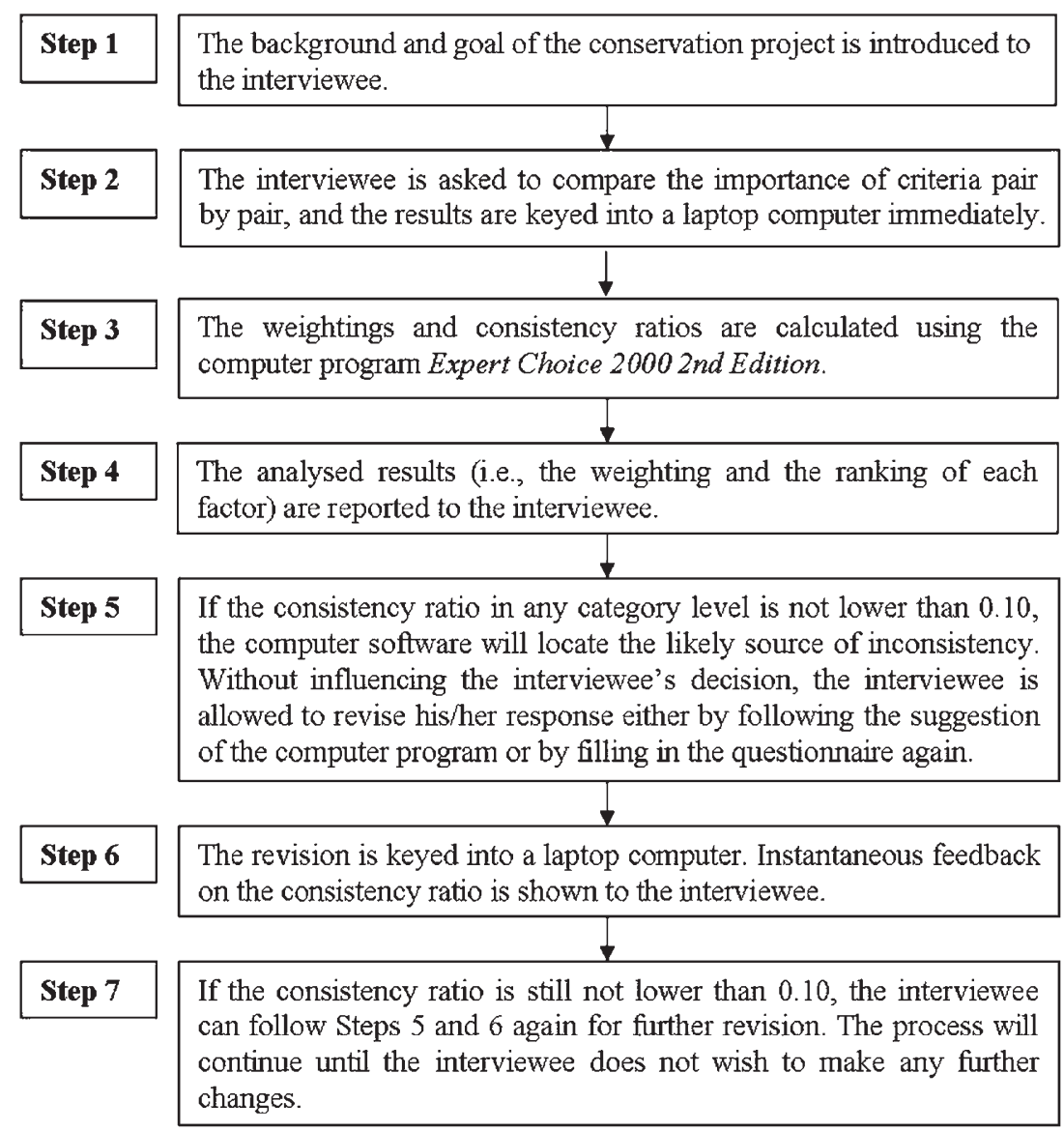

Figure 6: Procedures for carrying out AHP interviews (adapted from Ho et al., 2008)

interviewees and minimising the problems of differential interpretations of the terminologies, which would otherwise affect the interviewees' perceptions.

Pairwise comparisons were carried out on both criterion and sub-criterion levels. For the criterion level, the six decision criteria, namely 'Land Use', 'Design and Landscape', 'Infrastructural Impacts', 'Environmental Impacts', 'Engineering Concerns', and 'Financial Performance', were compared with respect to the relative importance towards the project goal perceived by the surveyed professionals. At the lower level, each subcriterion was compared with one another coming under the same criterion. The sets of criterion weightings obtained from different individuals were aggregated into one by means of the arithmetic mean. The resultant criterion weightings are summarised in Figure 7, which indicates that 'Historical Integrity', 'Compatibility', and 'Development Scale' were perceived as the most imperative decision factors by the surveyed professionals. Of the six criteria, 'Land Use' had the heaviest weighting.

After setting the weightings of the evaluation criteria, the decision makers can rank the options proposed by the private sector participants by rating the performance of the options on sub-criteria. Two approaches can be resorted in this exercise. The first approach is to devise a rating scheme for evaluating the options based on the criteria and sub-criteria identified. Each option is assessed using a 9-point scale with respect to each sub-criterion. For example, against the sub-criterion 'Compatibility', a score of 9 will be 


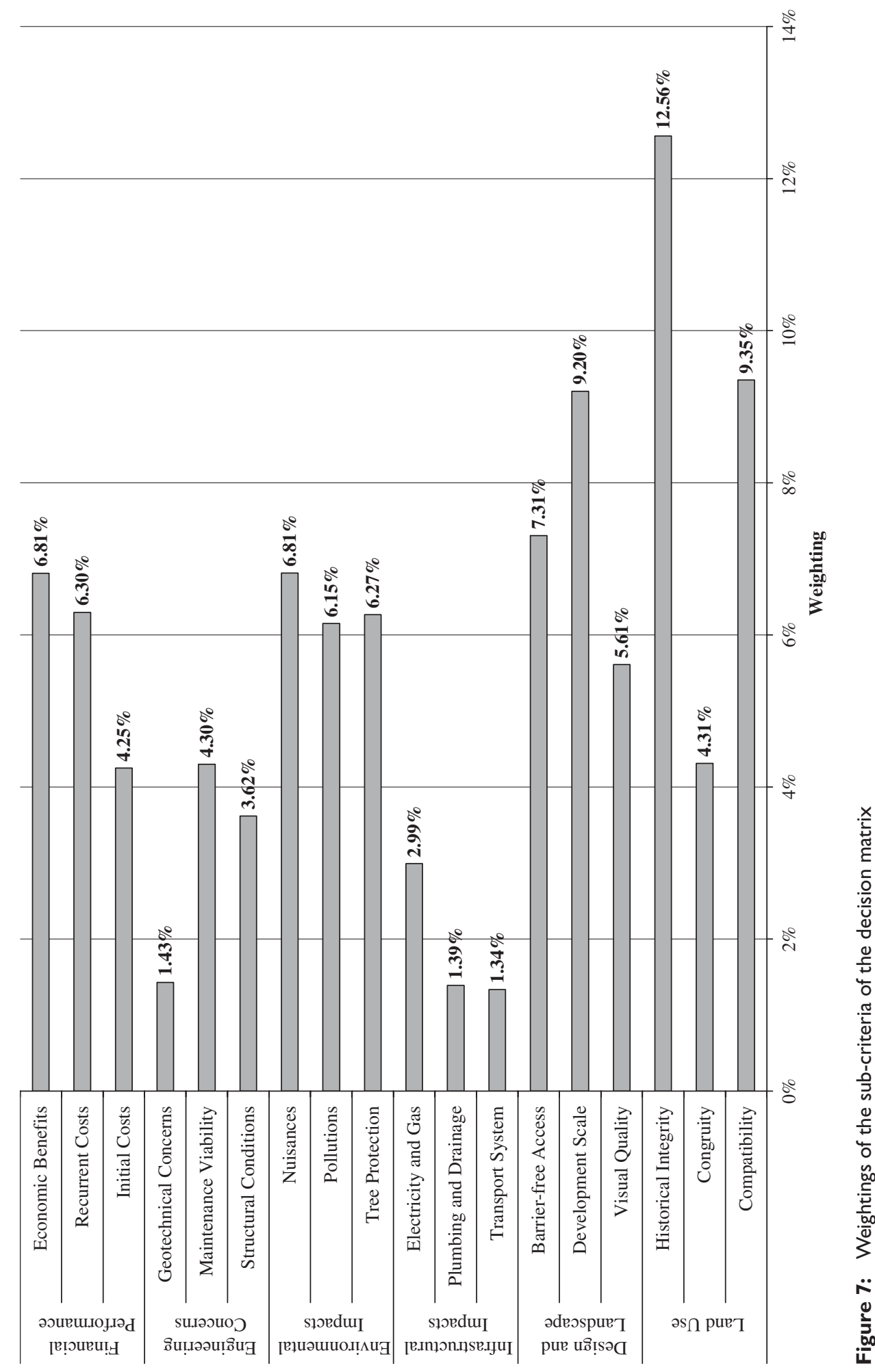


given to the option under examination if the use of the heritage perfectly fits the cultural and physical characteristics of the heritage, whereas a score of 5 will be given if the overall compatibility of land use is just about average. To ensure consistency of the rating, predetermined rating scales should be used and all evaluators should have a common understanding of the sub-criteria and the options to be rated.

In contrast, the second approach makes use of the AHP. In Figure 4, the bottom level contains a set of alternative options. Pairwise comparisons can be used to explore which option is the most preferable by the interviewees. The interviewees will be asked to compare the preference towards each pair of options with respect to every particular subcriterion, which is very similar to the case when we are soliciting their views towards the relative importance of the decision criteria. The only difference is that criterion weightings are calculated from the intensities of importance inputted by the interviewees in the latter case, whereas subjective scores for individual options are calculated from the levels of preference in the former case. No matter which rating method is used, a preference index is obtained from the weighted average of the ratings and scores assigned to each option with regard to the decision criteria and sub-criteria. Generally, the most favourable proposal is the one with the highest preference index.

\section{DISCUSION AND CONCLUSIONS}

Urban heritage conservation is by no means an easy task because a number of issues have been duly observed for a sustainable project. For example, while observing the economic gains generated from the built heritage, prudent preservation of the property should not be overlooked (Carter and Grimwade, 1997). Owing to its multipart nature, urban heritage conservation often creates many difficulties in the decision-making process. This paper offers a proposal on the MCDM methodology to deal with the complex decision-making problems for urban heritage conservation. To achieve more scientific and objective results, the AHP was used to decide the weightings for each criterion identified with respect to the overall project objective. This approach also improves the stakeholders' satisfaction through improved transparency in the ranking process and their increasing awareness of and participation in the process. Such a proposal is particularly timely in Hong Kong because the government launched the Revitalising Historic Buildings Through Partnership Scheme in 2007. Under this scheme, non-profit-making organisations are invited to submit proposals on running social enterprises in selected government-owned historic buildings (Commissioner for Heritage's Office, 2007). ${ }^{4}$ In evaluating the proposals, attention is paid to how the historical significance of the buildings can be brought out effectively, how the historic buildings would be preserved, the social value of the proposal and the financial viability of the social enterprises, etc. In this light, the MCDM model developed in this study can be adapted to evaluate the proposals for the partnership scheme.

It is beyond any argument that the criteria used in a ranking process and their weightings may be different for various projects to reflect the differences in the objectives, complexity, and environmental constraints of these projects. Therefore, to attempt to arrive at a universal set of weightings may be far from practical. Further studies are recommended to explore whether a universal set of criterion weightings can be applied to conservation projects of different scales and natures. Nonetheless, although the above methodology was tailored mainly to the selection of the most suitable proposals for urban heritage conservation, the concepts and principles could be extended easily to other conservation-related applications like prioritising maintenance needs for a list of historic buildings. 


\section{Notes}

1 Since the completion of its construction in 1884, the FMPHQ has been used as the base for the Marine Police of Hong Kong until 1997 except for the period of Japanese Occupation in 1941-1945 (Commissioner for Heritage's Office, 2008). The site comprises several structures, including a main building, a stable block, and a signal tower.

2 According to the Development Bureau (2007), a group led by the Ho-Tung family submitted a conceptual proposal to the then chief executive, asking the government to dispose the Compound by private treaty grant at nominal premium to a non-profit making organisation which would turn the Compound into a visual arts academy. Later in April 2007, the Hong Kong Jockey Club proposed to financially sponsor the conversion of the Compound into a mixed-use development with commercial facilities but at the same time requesting to build a new iconic structure on the site. Yet, the government has not decided to accept any of these proposals.

3 The 20 professionals include architects, building surveyors, structural engineers, town planners, and builders specialised in built heritage conservation.

4 The first batch of historic buildings available for bidding included the Old Tai Po Police Station, Old Tai O Police Station, Lui Seng Chun, Lai Chi Kok Hospital, North Kowloon Magistracy, Fong Yuen Study Hall, and Mei Ho House.

\section{References}

Aas, C., Ladkin, A. and Fletcher, J. (2005) 'Stakeholder collaboration and heritage management', Annals of Tourism Research, 32(1), 28-48.

Antiquities and Monuments Office. (2000) Protecting Hong Kong's Heritage, Antiquities and Monuments Office, Hong Kong.

Bell, M.L., Hobbs, B.F., Elliot, E.M., Ellis, H. and Robinson, Z. (2000) 'An evaluation of multi-criteria decision-making methods in integrated assessment of climate policy', in Haimes, Y.Y. and Steuer, R.E. (eds) Research and Practice in Multiple Criteria Decision Making, Springer, Berlin, pp. 228-237.

Bizzarro, F. and Nijkamp, P. (1997) 'Integrated conservation of cultural built heritage', in Brandon, P.S., Lobardi, P.L. and Bentivegna, V. (eds) Evaluation of the Built Environment for Sustainability, E \& FN Spon, London, pp. 451471.

Bouyssou, D. and Vincke, P. (1997) 'Ranking alternatives on the basis of preference relations: a progress report with special emphasis on outranking relationships', Journal of Multi-criteria Decision Analysis, 6(2), 77-85.

Carter, B. and Grimwade, G. (1997) 'Balancing use and preservation in cultural heritage management', International Journal of Heritage Studies, 3(1), 45-53.

Chang, T.C., Milne, S., Fallon, D. and Pohlmann, C. (1996) 'Urban heritage tourism: the global-local nexus', Annals of Tourism Research, 23(2), 284-305.

Chu, C. and Uebegang, K. (2002) Saving Hong Kong's Cultural Heritage, Civil Exchange, Hong Kong.

City Planning Consultant Limited. (1996) Study on Development Opportunities of the Former Marine Police Headquarters Site in Tsim Sha Tsui, City Planning Consultant Limited, Hong Kong.

Commissioner for Heritage's Office. (2007) 'Revitalising historic buildings through participation scheme: about the scheme', available at http://www.heritage.gov.hk/en/rhbtp/about.htm', accessed on 1st August, 2008.

Commissioner for Heritage's Office. (2008) 'Declared monuments: Former Police Headquarters Compound', available at http://www.heritage.gov.hk/en/buildings/monuments_51.htm', accessed on 1st August, 2008.

Crott, T. (1994) 'What price access? Visitor impact on heritage in trust', in Fladmark, J.M. (ed) Cultural Tourism, Donhead, London, pp. 169-178.

Cuthbert, A.R. (1983) Conservation and Capital Accumulation in Hong Kong, Centre of Urban Studies and Planning, University of Hong Kong, Hong Kong.

Development Bureau. (2007) Adaptive Reuse of the Central Police Station Compound: The Hong Kong Jockey Club's Proposal, Legislative Council Brief, Legislative Council, Hong Kong.

Henderson, J.C. (2002) 'Heritage attractions and tourism development in Asia: a comparative study of Hong Kong and Singapore', International Journal of Tourism Research, 4(5), 337-344.

Ho, D.C.W., Chau, K.W., Cheung, A.K.C., Yau, Y., Wong, S.K., Leung, H.F., Lau, S.S.Y. and Wong, W.S. (2008) 'A survey of the health and safety conditions of apartment buildings in Hong Kong', Building and Environment, 43(5), 764-775.

Hong Kong Special Administrative Region Government. (2004) 'Government committed to preserve the Central Police Station', available at http://www.info.gov.hk/gia/general/200409/20/0920246.htm, accessed on 1st March, 2008. 
Hsu, B.F.C. (2001) A Treatise on HKSAR Tax Law, Hong Kong University Press, Hong Kong.

Hutter, M. (1997) 'Economic perspectives on culture heritage: an introduction', in Hutter, M. and Rizzo, I. (eds) Economic Perspectives on Cultural Heritage, Macmillan Press, London, pp. 3-12.

Kiang, H.C. (2004) 'Preserving the cultural (built) heritage of cities', in Freire, M. and Yuen, B.K.P. (eds) Enhancing Urban Management in East Asian, Ashgate, Aldershot, pp. 239-256.

Leask, A. and Goulding, P. (1996) 'What price our heritage? A study of the role and contribution of revenue management in Scotland's heritage based visitor attractions in Robinson, M., Evans, N. and Callaghan, P. (eds) Managing Cultural Resources for the Tourist, Business Education, Sunderland, pp. 239-270.

Li, Y. and Lo, R.L.B. (2005) 'Opportunities and constraints of heritage tourism in Hong Kong's changing cultural landscape', Tourism and Hospitality Research, 5(4), 322-345.

Lung, D.P.Y. (1994) 'Are Hong Kong's planners to be condemned by history? The role of town planners in heritage conservation', Planning and Development, 10, 27-33.

McIntyre, C. and Parfitt, M.K. (1988) 'Decision support system for residential land development site selection process', Journal of Architectural Engineering, 4(4), 125-131.

Pöyhönen, M. and Hämäläinen, R.P. (2001) 'On the convergence of multiattribute weighting methods', European Journal of Operational Research, 129(3), 569-585.

Saaty, T.L. (1980) The Analytic Hierarchy Process, McGraw-Hill, New York.

Saaty, T.L. (1988) The Analytic Hierarchy Process: Planning Priority Setting, Resource Allocation, RWS Publications, Pittsburgh, PA.

Savage, L.J. (1954) The Foundations of Statistics, Wiley, New York, NY.

Schoemaker, P.J. and Waid, C.C. (1982) 'An experimental comparison of different approaches to determining weights in additive utility models', Management Science, 28(2), 182-196.

Shen, Q. and Spedding, A. (1998) 'Priority setting in planned maintenance — practical issues in using the multi-attribute approach', Building Research and Information, 26(3), 169-180.

South China Morning Post. (2004a) 'Site controversy back on the boil', South China Morning Post, City 3, 6th October. South China Morning Post. (2004b) 'Protesters join hands to preserve historic site', South China Morning Post, City 3 , 25th October.

Triantaphyllou, E. and Mann, S.H. (1990) 'An evaluation of the eigenvalue approach for determining the membership values in fuzzy sets', Fuzzy Sets and Systems, 35(3), 295-301.

Triantaphyllou, E. and Mann, S.H. (1995) 'Using the analytic hierarchy process for decision making in engineering applications: some challenges', Industrial Engineering Applications and Practices, 2(1), 35-44.

von Neumann, J. and Morgenstern, O. (1947) Theory of Games and Economic Behaviour, Princeton University Press, Princeton.

Watson, S.R. and Freeling, A.N.S. (1982) 'Assessing attribute weights', Omega, 10(5), 582-585.

Wong, G. (1999) 'Multi-criteria decision-aid for building professionals', The Journal of Building Surveying, 1, 5-10. 